\title{
Benchmarking and Ranking of Quoted Manufacturing Companies in Nigeria: A Data Envelopment Analysis Approach
}

\author{
Ifuero Osad Osamwonyi ${ }^{1} \&$ Kennedy Imafidon ${ }^{2}$ \\ ${ }^{1}$ Department of Banking and Finance, University of Benin, Benin City, Nigeria \\ 2 Department of Business Administration, Ambrose Alli University, Ekpoma, Nigeria \\ Correspondence: Ifuero Osad Osamwonyi, Professor of Finance, Department of Banking and Finance, University of \\ Benin, Benin City, Nigeria
}

Received: March 11, 2015

Accepted: July 23, 2015

Online Published: September 4, 2015

doi:10.5430/ijfr.v6n4p90

URL: http://dx.doi.org/10.5430/ijfr.v6n4p90

\begin{abstract}
The objective of this study is to identify quoted manufacturing companies in Nigeria that can be used as benchmark for less efficient companies. To achieve this objective, the study adopted the output orientated DEA model with total asset, shareholder's equity, cost of goods sold and operating expenses as input variables, while the output variables are sales/turnover, net profit, return on asset, and return on equity. The output orientated DEAP Version 2.1 package with variable return to scale assumption [multi-stage DEA approach] was employed. The analysis revealed the inefficient quoted manufacturing companies that should emulate the efficient ones in terms of input-output mix. The result indicates that twenty-seven companies can be used for benchmarking. The study recommends possible merger of the inefficient companies with efficient ones in the same sector in order to strengthen them and enhance their contributions to development of Nigeria.
\end{abstract}

Keywords: benchmarking, manufacturing, Data Envelopment Analysis

\section{Introduction}

The advancement of knowledge, science and technology is transforming the globe into a borderless world. The multi-dimensional changes do not only affect physical environment but also business environment. Business organizations both big and small, public and private must be ready to meet and adapt to challenges emerging from these changes if they are to survive and remain in business as major players. One of the strategies is taking advantage of benchmarking using ranked performance of companies in the relevant sector.

Numerous studies on benchmarking and ranking of manufacturing companies using Data Envelopment Analysis [DEA] have been conducted and reported worldwide but such studies are scanty in Nigeria and indeed in Africa. This study is therefore conducted to benchmark and rank quoted manufacturing companies in Nigeria using DEA approach, thus providing the base for interested companies to strategize.

\section{Literature Review}

Peer Groups: DEA analysis identifies for each inefficient unit a set of excellent units, called a peer group, which includes those units that are efficient if evaluated with the optimal system of weights of an inefficient unit. The peer group, made up of Decision Making Units [DMUs] which are characterized by operating methods similar to the inefficient unit being examined, provides transformation benchmark. Indeed, these units correspond to the DMUs for which the first and the second members of constraints are equal:

$$
E_{j}=\left[j: \sum_{r \in K} u_{r}^{*} y_{r j}=\sum_{i \in H} v_{i}^{*} x_{i j}\right]
$$

Alternatively, with respect to formulation (1), the peer group consists of those units whose variable $\lambda_{\mathrm{j}}$ in the optimal solution is strictly positive:

$$
E_{j}=\left\{j: \lambda_{j}^{*}>0\right\}
$$


Note that within a peer group a few excellent units more than others may represent a reasonable benchmark for comparison. The relative importance of a unit belonging to a peer group depends on the value of the corresponding variable $\lambda_{j}$ in the optimal solution of the dual model. The analysis of peer groups allows one to differentiate between really efficient units and apparently efficient units for which the choice of an optimal system of weights conceals some abnormal behaviour. To achieve this distinction, it is necessary to evaluate how often each efficient unit belongs to a peer group.

Benchmarking in Data Envelopment Analysis: For every inefficient DMU, DEA identifies a set of corresponding efficient units that can be utilized as benchmarks for improvement. The benchmarks can be obtained from the dual problem.

$$
\begin{gathered}
\operatorname{Min} \theta \\
\text { s.t } \sum_{i=1}^{n} \lambda_{i} x_{j i}-\theta x_{j p} \leq 0 \quad \forall j \\
\sum_{i=1}^{n} \lambda_{i} y_{k i}-y_{k p} \geq 0 \quad \forall k \\
\lambda_{i} \geq 0 \quad \forall i
\end{gathered}
$$

where

$\theta=$ efficiency score, and

$\lambda s=$ dual variables.

A test DMU is inefficient if a composite DMU (linear combination of units in the set) can be identified which utilizes less input than the test DMU while maintaining at least the same output levels. Consequently, the units involved in the construction of the composite DMU can be utilized as benchmarks for improving the inefficient test DMU. DEA also permits the computing of the necessary improvements in inputs and outputs of the inefficient unit. However, it should be noted that DEA is primarily a diagnostic tool and does not prescribe any reengineering strategies to make inefficient units efficient.

Although benchmarking in DEA allows for the identification of targets for improvements, it has limitations. A difficulty recognized in the literature is that an inefficient DMU and its benchmarks may not be inherently similar in their operating practices. This is primarily due to the fact that the composite DMU that dominates the inefficient DMU does not exist in the same sector. To overcome these problems researchers have utilized performance-based clustering methods for identifying more appropriate benchmarks (Doyle \& Green, 1994; Talluri \& Sarkis, 1997). These methods cluster inherently similar DMUs into groups, and the best performer in each cluster serves as a benchmark for other DMUs in that cluster. Identifying and sharing good operating practices, one may hope to achieve an improvement in the performance of all units being compared.

The need to identify the true efficient units, for the purpose of defining the best operating practices, stems from the principle itself on which DEA is grounded, as it allows each unit to evaluate its own degree of efficiency by choosing the most advantageous structure of weights for inputs and outputs. A unit might appear efficient by the deliberate attachment of a non-negligible weight to a limited subset of inputs and outputs. Interestingly, those inputs and outputs that receive greater weights may be less critical than other factors which are intimately connected to the primary activity performed by the relevant units. In order to internalize best practices, it is expedient to select the units that are really efficient, that is, those units whose efficiency score are neutral to the system of weights selected. One can resort to a combination of different methods: cross-efficiency analysis, evaluation of virtual inputs and virtual outputs, and weight restrictions to differentiate these units.

Cross-Efficiency Analysis: Cross-efficiency analysis is based on the definition of the efficiency matrix. It provides information on the nature of the weights system adopted by the units for their own efficiency evaluation. The square efficiency matrix employed contains as many rows and columns as there are units being compared. The generic element $\theta_{\mathrm{ij}}$ of the matrix represents the efficiency of $\mathrm{DMU}_{\mathrm{j}}$ evaluated through the optimal weights structure for $\mathrm{DMU}_{\mathrm{i}}$, while the element $\theta_{\mathrm{jj}}$ provides the efficiency of $\mathrm{DMU}_{\mathrm{j}}$ calculated using its own optimal weights. If $\mathrm{DUM}_{\mathrm{j}}$ is 
efficient (i.e. if $\theta_{\mathrm{jj}}=1$ ), when it exhibits a behaviour focused on a given dimension with respect to the other units, the efficiency values in the column corresponding to $\mathrm{DMU}_{\mathrm{j}}$ will be less than 1 .

The efficiency matrix generates two quantities. The first is the average efficiency of a unit with respect to the optimal weights system for the different units, obtained as the average of the values in the $j$ th column. The second is the average efficiency of a unit which is measured applying its optimal system of weights to the other units; obtained by averaging the values in the row associated with the relevant unit. The difference between the efficiency score $\theta_{\mathrm{jj}}$ of $\mathrm{DMU}_{\mathrm{j}}$ and the efficiency obtained as the average of the values in the jth column indicates how much the unit relies on a system of weights conforming with the one used by the other units. If the difference between the two terms is significant, $\mathrm{DMU}_{\mathrm{j}}$ may have selected a structure of weights that is not shared by the other DMUs in order to look efficient. Cross-efficiency methods evaluate the performance of a DMU with respect to the optimal input and output weights $\left(v_{k}\right.$ and $u_{j}$ ) of other DMUs. The resulting evaluations can be aggregated in a Cross Efficiency Matrix (CEM). In the CEM, the element in $i$ th row and $j$ th column represents the efficiency of DMU $j$ when evaluated with respect to the optimal weights of DMU. A good overall performing DMU should have several high cross-efficiency scores along its column while poorly performing DMU should have several low values. Thus effectively differentiating between good and poor performering DMUs. Some techniques have been proposed for obtaining robust factor weights for use in the construction of CEM. Doyle and Greene (1994) have developed a set of formulations, and the most appropriate is the aggressive formulation, which identifies optimal weights that not only maximize the efficiency of a unit but also minimize the efficiency of the average unit that is constructed from the other, ( $n-1$ unit).

Talluri (2000) proposed a variation to the Doyle and Greene model, which compares a pair of DMUs each time. In this model, the target DMU (evaluator) not only maximizes its efficiency score but also minimizes the efficiency score of each competitor, in turn. Therefore, the optimal weights of the target DMU can involve multiple strategies (optimal solutions or the input and output weights), that can be incorporated into a CEM for benchmarks identification.

Sarkis and Talluri (1997) extended the above case to include both cardinal and ordinal input and output factors, which is based on the work of Cook, Kress, and Seiford, (1996). They proposed a combination of models that allowed for effective ranking of DMUs in the presence of both quantitative as well as qualitative factors. Other ranking methods that do not specifically include cross-efficiencies are those proposed by Rousseau and Semple (1995), and Andersen and Petersen (1993). Rousseau and Semple (1995) approach uses a two-person ratio efficiency game, by formulating a unique set of weights in a single phase as opposed to the two-phase approaches. Andersen and Petersen (1993) proposed a ranking model where the test DMU is removed from the constraint set allowing the DMU to achieve an efficiency score of greater than 1.

Virtual Inputs and Virtual Output: Virtual inputs and virtual outputs provide information on the relative importance such that the specific competencies/weaknesses of each unit are identified. The virtual inputs of a DMU are defined as the product of the inputs used by the unit and the corresponding optimal weights. Similarly, virtual outputs are given by the product of the outputs of the unit and the associated optimal weights. Inputs and outputs for which the unit shows high virtual scores indicate the activities in which the unit being analyzed appears particularly efficient.

Weight Restrictions: To separate the units that are really efficient from those whose efficiency score largely depends on the selected weights system, we may impose some restrictions on the value of the weights to be associated with inputs and outputs. Thus, these restrictions translate into the definition of maximum thresholds for the weight of specific outputs or minimum thresholds for the weight of specific inputs. Despite possible restrictions on the weights, the units still enjoy certain flexibility in the choice of multiplicative factors for inputs and outputs. Methods for incorporating weight restrictions are suggested by Charnes et al (1990), Dyson and Thanassoulis (1988), Thompson et al (1986, 1990, 1995), and Wong and Beasley (1990).

Efficiency Changes Over Time: In order to capture the variations of efficiency over time, Charnes, Clark, Cooper and Golany (1985) proposed a technique called 'window analysis' in DEA. Window analysis assesses the performance of a DMU over time by treating it as a different entity in each time period. This method allows for 
tracking the performance of a unit or a process. A variation is proposed by Talluri and Sarkis (1997) to effectively monitor the performance of a unit over time and assist in process improvement and benchmarking.

\section{Method}

The population of the study comprises of all quoted manufacturing companies on the Nigerian Stock Exchange. The study focuses on the eighty-six companies which are into manufacturing. The manufacturing companies comprises are grouped into the following sectors: breweries, building materials, chemical and paints, computer and office equipment, conglomerates, engineering and technology, food/beverages and tobacco, health care, industrial/domestic products, packages, printing and publishing and textiles (Jide, 2010). However, some of the companies in agriculture/allied and petroleum (marketing) sectors are also included.

Due to its non parametric and multi-dimensional nature, DEA approach generally requires large numbers of DMUs to produce statistically meaningful results (Simar \& Wilson, 2000). Therefore, DEA is highly vulnerable to data problems. The sample size of fifty-eight companies was chosen, using Yaro Yamane formula with 5\% level of significance. The elements are selected using stratified random sampling.

The study employed secondary data for 2004 to 2010 from Nigerian Stock Exchange Factbooks, Annual reports and financial statements of the companies under study. The input variables of the companies considered are total asset, shareholder's equity, cost of goods sold and operating expenses while the output variables are sales/turnover, net profit, return on asset and return on equity.

\subsection{Measurement of the Variables}

Data envelopment analysis can be applied to firms producing revenue (Ephraim, 2000), which can be done by converting the financial performance measures to the firm's technical efficiency equivalents. The first and very crucial step in conducting DEA is the determination of inputs and outputs. The main important point in this process is that the input-output variables should be chosen in accordance with the type of efficiency being assessed (Sherman \& Rupert, 2006). It is well known that DEA becomes sensitive to variable selection as the number of variables increases; that is, the ability to discriminate between the DMUs decreases (Smith, 1997). To preserve the discriminatory power of DEA therefore, the number of inputs and outputs should be kept at a reasonable level. Diagnostic checks do not exist for model misspecification in DEA (Galagedera \& Silvapulle, 2003). However, Raab and Lichty (2002) suggest a general rule of thumb - the minimum number of DMUs is greater than three times the number of inputs plus outputs. Another rule of thumb for selecting an appropriate sample size is to ensure that the sample size is at least three times larger than the sum of inputs and outputs (Stern, Mehrez, \& Barboy, 1994). Input variables are Total asset, Shareholder's equity, Cost of goods sold, and Operating expenses. Output variables are Sales/turnover, Return on equity, Return on asset, and Net profit. For data analysis, the output orientated DEAP Version 2.1 written by Coelli (1996) is employed.

\section{Analysis of Data and Discussion of Findings}

The DEA result is shown in Table 1.

Table 1. Peers and peer count of quoted manufacturing companies in Nigeria for benchmarking

\begin{tabular}{cccc}
\hline /N & Companies & List of peers & $\begin{array}{c}\text { Peer } \\
\text { counts }\end{array}$ \\
\hline 1 & LIVESTOCK & NIG. BAG, TRIP. GEE, INT. BREW \\
2 & FTN COCOA & 4 \\
3 & PRESCO & 1 \\
4 & OKOMU & FTN COCOA, ACADEMY, NCR, LARFARGE, P.Z & 1 \\
5 & GUINNESS & TRIP. GEE, NIG. BAG, NORTH. FLOUR, SCOA, & 0 \\
6 & NIG. BREW & ALUMI. EXTRA & 0 \\
& & & 3 \\
7 & INT. BREW & P.Z, LARFARGE, UTC & 0 \\
8 & ASHAKA & & 1 \\
9 & CEMENT CO. & & 15 \\
10 & LARFARGE & NIG. ROPES & NORTH FLOUR, FTN COCOA, ALUMI. EXTRA, NIG. \\
11 & AFRI. PAINTS & & 0 \\
12 & &
\end{tabular}




\begin{tabular}{|c|c|c|c|}
\hline 13 & BERG. PAINTS & LARFARGE, NCR, P.Z, UTC & 0 \\
\hline 14 & CAPL & VITAFOAM & 0 \\
\hline 15 & IPWA & FTN COCOA, P.Z, ALUMI EXTRA, UTC & 0 \\
\hline 16 & PREM. PAINT & & 0 \\
\hline 17 & NCR & & 5 \\
\hline 18 & THOMAS & & 0 \\
\hline 19 & TRIP GEE & & 7 \\
\hline 20 & LEVENTIS & & 0 \\
\hline 21 & CHELLARMS & & 0 \\
\hline 22 & P.Z & & 8 \\
\hline 23 & SCOA & & 1 \\
\hline 24 & UNILEVER & UNILEVER, ACADEMY & 0 \\
\hline 25 & CUTIX & & 0 \\
\hline 26 & NIG. WIRE & UTC, NCR, P.Z & 0 \\
\hline 27 & 7-UP & P.Z, LARFARE, UTC & 0 \\
\hline 28 & CADBURY & ACADEMY, LARFARGE & 0 \\
\hline 29 & FLOUR MILL & ALUMI. EXTRA, UNT. TEXT, TRIP. GEE, LARFARGE & 0 \\
\hline 30 & NAT. SALT & & 0 \\
\hline 31 & NORTH FLOUR & & 5 \\
\hline 32 & NESTLE & UTC, P.Z, NORTH FLOUR, ALUMI-EXTRA & 0 \\
\hline 33 & NIG. BOTTLING & VITAFOAM, ACADEMY, LARFARGE & 0 \\
\hline 34 & P.S. MAND & & 0 \\
\hline 35 & UTC & & 8 \\
\hline 36 & GLAXO & NIG. BAG, ALUMI EXTRA, TRIP. GEE, UNT. TEXT & 0 \\
\hline 37 & M \& BAKER & & 0 \\
\hline 38 & MORISON & & 0 \\
\hline 39 & NEIMETH & TRIP GEE, LARFARGE, CEMENT CO, PRESCO & 0 \\
\hline 40 & PHARMA & UTC, LARFARGE & 1 \\
\hline 41 & ALUM. EXTR & & 9 \\
\hline 42 & BOCGAS & & 0 \\
\hline 43 & NIG. ENAL & & 0 \\
\hline 44 & VITAFOAM & NCR, LARFARGE, P.Z, UTC & 4 \\
\hline 45 & AVON & & 0 \\
\hline 46 & BETA & $\begin{array}{c}\text { ALUMI EXTRA, NCR, ACADEMY, FTN COCOA, } \\
\text { NORTH FLOUR }\end{array}$ & 0 \\
\hline 47 & NAMPAK & & 0 \\
\hline 48 & NIG. BAG & & 3 \\
\hline 49 & GREIF & & 0 \\
\hline 50 & POLY & & 0 \\
\hline 51 & MRS OIL & ACADEMY, LARFARGE & 0 \\
\hline 52 & CONOIL & ALUMI EXTRA, UNT. TEXT, TRIP GEE & 0 \\
\hline 53 & ETERNA & $\begin{array}{c}\text { ACADEMY, LARFARGE, NIG. ROPES, TRIP GEE, } \\
\text { INT. BREW }\end{array}$ & 0 \\
\hline 54 & MOBIL & ACADEMY, LARFARGE & 0 \\
\hline 55 & ACADEMY & & 8 \\
\hline 56 & LONGMAN & VITAFOAM & 0 \\
\hline 57 & UNIPRESS & $\begin{array}{c}\text { PHARMA, INT. BREW, NIG. ROPES, NORTH. FLOUR, } \\
\text { ALUMI EXTRA }\end{array}$ & 0 \\
\hline 58 & UNT.TEXT & & 3 \\
\hline
\end{tabular}

Source: DEA print out 
The Table 1 will be used for two analyses. Firstly, the identification of the twenty-seven inefficient companies that need to emulate the efficient ones in order to be on the production possibility frontier. Livestock should emulate Nig.Bag, Trip.Gee and NCR. Guinness should emulate FTN Cocoa, Academy, NCR, Larfarge, and Afri.Paints. Nig.Brew should emulate Trip.Gee, Nig Bag, North.Flour, SCOA, and Alum.Extru. Ashaka should emulate FTN Cocoa, Larfarge and UTC. Afri.Paints should emulate North.Flour, FTN Cocoa, Alum.Extru and Nig.Ropes. Berg.Paints should emulate Larfarge, NCR, P.Z, and UTC. CAPL should emulate Vitafoam. IPWA should emulate FTN Cocoa, P.Z, Alum.Extru and UTC. Unilever should emulate Larfarge and Academy. Nig.Wire should emulate UTC, NCR and P.Z. 7-UP should emulate P.Z, Larfarge and UTC. Cadbury should emulate Academy and Larfarge. Flour Mill should emulate Alum.Extr, Unt.Text, Trip.Gee and Larfarge. Nestle should emulate company UTC, P.Z, Nort.Flour and Alum.Extru. Nig.Bottling should emulate Vitafoam, Academy, and Larfarge. Glaxo should emulate Nig.Bag, Alumi.Extru, Trip.Gee and Unt.Text. Neimeth should emulate Trip.Gee, Larfarge, Cement and Presco. Bocgas should emulate Larfarge, Vitafoam and Okomu. Nig.Enal should emulate UTC and Larfarge. Nampak should emulate company NCR, Larfarge, P.Z and UTC. Grief should emulate Alumi.Extru, NCR, Academy, FTN Cocoa and North.Flour. MRS Oil should emulate Academy and Larfarge. Conoil should emulate Alumi.Extru, Unt.Text, and Trip.Gee. Eterna should emulate Academy, Larfarge, Nig.Ropes, Trip.Gee and Int.Brew. Mobil should emulate Academy and Larfarge. Longman should emulate Longman should emulate Vitafoam. Finally, Unipress should emulate Pharma, Int.Brew, Nig.Ropes, NorthFlour, and Alumi.Extru.

Secondly, the peer count analysis is about the number of times a DMU is used to benchmark as a standard for emulation for other $\mathrm{DMU}_{\mathrm{s}}$. The higher the number of peer count for any DMU, the more desirable is it for benchmarking. From the table above Larfarge have fifteen peer counts. This is the highest peer count, showing that this company is operating at the most desirable point on the frontier. FTN Cocoa has four peer counts, Presco has one peer count, Okomu has one peer count, Int.Brew has three peer counts, Cement Co has one peer count, Nig.Ropes has three peer counts, NCR has five peer counts, Trip.Gee has seven peer counts, P.Z has eight peer counts, SCOA has one peer count, North.Flour has five peer counts, UTC has eight peer counts, Pharma has one peer count, Vitafoam has four peer counts, Nig. Bag has three peer counts, Academy has eight peer counts while Unt.Text has three peer counts. The implication of this analysis is that the input-output mix of these companies provides benchmarks.

\section{DEA Ranking of Efficient Quoted Manufacturing Companies in Nigeria}

Table 2. DEA ranking of the efficiency of quoted manufacturing companies in Nigeria

\begin{tabular}{|c|c|c|c|c|c|c|c|}
\hline $\begin{array}{l}\text { Firm } \\
\text { Rank }\end{array}$ & $\begin{array}{l}\text { DMU } \\
\text { (Companies) }\end{array}$ & $\begin{array}{l}\text { Constant Return to } \\
\text { Scale } \\
\text { Technical Efficiency }\end{array}$ & $\begin{array}{l}\text { Variable Return to } \\
\text { Scale Technical } \\
\text { Efficiency }\end{array}$ & $\begin{array}{l}\text { Scale } \\
\text { Efficiency. }\end{array}$ & $\begin{array}{l}\text { List of Peers } \\
\text { under VRS }\end{array}$ & $\begin{array}{l}\text { DEA. } \\
\text { Rank }\end{array}$ & Remarks \\
\hline 3 & PRESCO & 1.000 & 1.000 & 1.000 & [3] & 01 & crs \\
\hline 4 & OKOMU & 1.000 & 1.000 & 1.000 & {$[4]$} & 02 & crs \\
\hline 7 & INT BREW & 1.000 & 1.000 & 1.000 & [7] & 03 & crs \\
\hline 9 & CEMENT CO & 1.000 & 1.000 & 1.000 & [9] & 04 & crs \\
\hline 10 & LARFARGE & 1.000 & 1.000 & 1.000 & {$[10]$} & 05 & crs \\
\hline 11 & NIG.ROPES & 1.000 & 1.000 & 1.000 & {$[11]$} & 06 & crs \\
\hline 16 & PRE.PAINT & 1.000 & 1.000 & 1.000 & {$[16]$} & 07 & crs \\
\hline 18 & THOMAS & 1.000 & 1.000 & 1.000 & {$[18]$} & 08 & crs \\
\hline 19 & TRIP.GEE & 1.000 & 1.000 & 1.000 & [19] & 09 & crs \\
\hline 20 & LEVENTIS & 1.000 & 1.000 & 1.000 & {$[20]$} & 10 & crs \\
\hline 21 & CHELLARMS & 1.000 & 1.000 & 1.000 & {$[21]$} & 11 & crs \\
\hline 23 & SCOA & 1.000 & 1.000 & 1.000 & [23] & 12 & crs \\
\hline 25 & CUTIX & 1.000 & 1.000 & 1.000 & {$[25]$} & 13 & crs \\
\hline 30 & NAT.SALT & 1.000 & 1.000 & 1.000 & {$[30]$} & 14 & crs \\
\hline 31 & NORTH.FLOUR & 1.000 & 1.000 & 1.000 & {$[31]$} & 15 & crs \\
\hline 35 & UTC & 1.000 & 1.000 & 1.000 & {$[35]$} & 16 & crs \\
\hline 38 & MORISON & 1.000 & 1.000 & 1.000 & {$[38]$} & 17 & crs \\
\hline
\end{tabular}




\begin{tabular}{|c|c|c|c|c|c|c|c|}
\hline 40 & PHARMA & 1.000 & 1.000 & 1.000 & [40] & 18 & crs \\
\hline 41 & ALUM.EXTRU & 1.000 & 1.000 & 1.000 & [41] & 19 & crs \\
\hline 44 & VITAFOAM & 1.000 & 1.000 & 1.000 & [44] & 20 & crs \\
\hline 45 & AVON & 1.000 & 1.000 & 1.000 & {$[45]$} & 21 & crs \\
\hline 46 & BETA & 1.000 & 1.000 & 1.000 & {$[46]$} & 22 & crs \\
\hline 48 & NIG.BAG & 1.000 & 1.000 & 1.000 & {$[48]$} & 23 & crs \\
\hline 58 & UNT.TEXT & 1.000 & 1.000 & 1.000 & {$[58]$} & 24 & crs \\
\hline 55 & ACADEMY & 1.000 & 1.000 & 1.000 & {$[55]$} & 25 & crs \\
\hline 50 & POLY & 0.988 & 1.000 & 0.988 & {$[50]$} & 26 & drs \\
\hline 17 & NCR & 0.965 & 1.000 & 0.965 & [17] & 27 & drs \\
\hline 37 & MAY\&BAKER & 0.738 & 1.000 & 0.738 & [37] & 28 & $\mathrm{drs}$ \\
\hline 22 & P.Z & 0.641 & 1.000 & 0.641 & {$[22]$} & 29 & drs \\
\hline 34 & P.SMAND & 0.536 & 1.000 & 0.536 & [34] & 30 & drs \\
\hline 2 & FTN COCOA & 0.334 & 1.000 & 9.536 & {$[2]$} & 31 & drs \\
\hline 15 & IPWA & 0.305 & 0.984 & 0.310 & {$[2,22,41,35]$} & 32 & drs \\
\hline 26 & NIG.WIRE & 0.095 & 0.979 & 0.095 & {$[35,17,22]$} & 33 & drs \\
\hline 27 & 7-UP & 0.293 & 0.966 & 0.293 & {$[22,10,35]$} & 34 & drs \\
\hline 24 & UNILEVER & 0.243 & 0.948 & 0.257 & {$[10,55]$} & 35 & drs \\
\hline 33 & NIG.BOTTLING & 0.622 & 0.930 & 0.669 & {$[44,55,10]$} & 36 & drs \\
\hline 56 & LONGMAN & 0.318 & 0.926 & 0.343 & [44] & 37 & drs \\
\hline 6 & NIG.BREW & 0.891 & 0.923 & 0.966 & {$[19,48,31,23,4]$} & 38 & drs \\
\hline 57 & UNIPRESS & 0.810 & 0.901 & 0.900 & {$[40,7,11,31,41]$} & 39 & drs \\
\hline 13 & BERG.PAINTS & 0.309 & 0.873 & 0.354 & {$[10,17,22,35]$} & 40 & drs \\
\hline 14 & CAPL & 0.196 & 0.770 & 0.255 & [44] & 41 & drs \\
\hline 54 & MOBIL & 0.174 & 0.758 & 0.230 & {$[55,10]$} & 42 & drs \\
\hline 49 & GREIF & 0.470 & 0.701 & 0.671 & {$[41,17,55,2,31]$} & 43 & drs \\
\hline 1 & LIVESTOCK & 0.699 & 0.699 & 1.000 & {$[48,19,7]$} & 44 & drs \\
\hline 47 & NAMPAK & 0.195 & 0.696 & 0.280 & {$[17,10,22,35]$} & 45 & drs \\
\hline 43 & NIG.BAG & 0.265 & 0.689 & 0.384 & {$[35,10]$} & 46 & drs \\
\hline 28 & CADBURY & 0.174 & 0.675 & 0.257 & {$[55,10]$} & 47 & drs \\
\hline 29 & FLOUR MILL & 0.649 & 0.672 & 0.966 & {$[41,58,19,10]$} & 48 & drs \\
\hline 8 & ASHAKA & 0.131 & 0.579 & 0.226 & {$[22,10,35]$} & 49 & drs \\
\hline 5 & GIUNNESS & 0.313 & 0.554 & 0.565 & {$[2,55,17,10,12]$} & 50 & drs \\
\hline 32 & NESTLE & 0.422 & 0.556 & 0.759 & {$[35,22,31,41]$} & 51 & drs \\
\hline 51 & MRS OIL & 0.298 & 0.541 & 0.552 & {$[55,10]$} & 52 & drs \\
\hline 12 & AFRI.PAINTS & 0.376 & 0.520 & 0.723 & {$[31,2,41,11]$} & 53 & drs \\
\hline 53 & ETERNA & 0.393 & 0.423 & 0.929 & {$[55,10,11,19,7]$} & 54 & drs \\
\hline 52 & CONOIL & 0.364 & 0.366 & 0.995 & {$[41,58,19$} & 55 & irs \\
\hline 42 & BOCGAS & 0.127 & 0.296 & 0.429 & {$[10,44,4]$} & 56 & drs \\
\hline 36 & GLAXO & 0.242 & 0.254 & 0.952 & {$[48,41,19,58]$} & 57 & irs \\
\hline 39 & NEIMETH & 0.109 & 0.193 & 0.562 & {$[19,10,9,3]$} & 58 & drs \\
\hline
\end{tabular}

Source: DEA print out

The ranking analysis shows that the companies in the Agro/Allied sector were all efficient except livestock but operated in the region of constant return to scale. This means that they are efficient in the application of inputs resources. Another distinguishing feature of the ranking is that the companies in the computers and office equipment sector were all efficient; this may be associated with the nature of their operations. The ranking also revealed that the 
companies in the petroleum (marketing) sector were not efficient; this may be due to endemic corruption as revealed by the petroleum subsidy saga. The ranking finally indicates mixed results for other sectors where some were efficient while others were not. The inefficient companies have been given a benchmark to follow in order to be on the efficient frontier by the ranking table. It should be noted that this ranking is also useful for the rating of manufacturing companies in Nigeria.

\subsection{Some Discussion of Findings}

Benchmarking identifies a set of efficient DMUs that can be utilized as benchmarks for improvement. The study revealed the number of efficient companies that the inefficient companies should emulate. In other words, for the inefficient companies to operate on the production possibility frontier, they have to emulate the production processes of the efficient companies. The study shows that thirty-one companies can be used as benchmark for others, while twenty-seven companies have to emulate the thirty-one companies in order to improve on their efficiency. The study is in agreement with Mostafa (2007). The thirty-one companies provide a way for other companies to the frontier. It should be noted that the peer counts shows the number of time a company is a peer for others. In this case, the highest peer indicates that the company is operating at the most desirable point on the frontier to be emulated by other companies. The study confirmed the study by Nordin and Said (2010).

The study provides a method for rating the efficiency of quoted manufacturing companies in Nigeria by Rating Agencies and regulatory bodies such as the Manufacturer Association of Nigeria, NAFDAC, SON, NECA and Nigerian Chamber of Commerce and Industry. The rating of the companies is important to investors and lenders. Generally, the rating agency can use the method applied in the study to rate the performance of quoted manufacturing companies in Nigeria. Rating can also be on sector by sector basis. The sectoral analysis is necessary to capture sectoral heterogeneity. It also generates the efficient companies in Nigeria that can be benchmarked by the inefficient ones in order to increase the growth of the Nigerian economy.

\section{Conclusion}

The study utilized an output orientated DEA methodology to benchmark quoted manufacturing companies in Nigeria under the assumption of variable return to scale. The result indicates that the inefficient companies should emulate the efficient ones in terms of input-output mix in the same sector. The result further illustrates the use of peer units to identify the path to the efficient frontier. The policy implication of this study is that it enables government to identify focus for the development of the manufacturing sector. It also provides a framework for mergers and acquisitions in the capital market in Nigeria.

\section{References}

Anderse, P., \& Peterseen, N. (1993). A procedure for ranking efficiency units in data envelopment analysis. Management Science, 39, 1261-1264. http://dx.doi.org/10.1287/mnsc.39.10.1261

Charnes, A., Cooper, W., Clark, W., \& Galony, B. (1985). A Developmental study of data envelopment analysis in measuring the efficiency of maintenance units in US air forces. In R. Thompson and R.M, Thrall (Eds.), Annals of Operation Research, 2, 95-112.

Coelli, T. (1996). A guide to DEAP version 2.1: A data envelopment analysis (computer) program. CEPA Working Paper 96/08, University of New England, Australia.

Coelli, T. J., PrasadaRao, D. S., Odonnell, C. J, \& Battese, G. E. (2005). An introduction to efficiency and productivity analysis. New York: Springer Science Business Media.

Cook, W. D., Kress, M., \& Seiford, L. M. (1996). Data envelopment analysis in the presence of both quantitative and qualitative factors. Journal of the Operational Research Society, 47(7), 945-953. http://dx.doi.org/10.1057/jors.1996.120

Cooper, W., Lawrence, W., Seiford, L. M., \& Zhu, J. (1990). Data envelopment analysis: History, model and interpretations. Boston: Kluwer Academic.

Doyle, J., \& Green, R. (1994). Efficiency and cross-efficiency in DEA: Derivations, meaning and uses. Journal of the Operational Research Society, 45(5), 567-578. http://dx.doi.org/10.1057/jors.1994.84

Ephraim, W. C. (2000). Privatization and technical efficiency, evidence from Malawi Manufacturing, Department of Economics University of Malawi, Working Paper No. WC/03/00.

Galagedera, D., \& Silvapulle, P. (2003). Experimental evidence on robustness of data envelopment analysis. Journal of the Operational Research Society, 54, 654-660. http://dx.doi.org/10.1057/palgrave.jors.2601507 
Imafidon, K. (2012). Assessing the efficiency of quoted manufacturing companies in Nigeria: Data envelopment analysis approach: A Ph.D thesis submitted to the Department of Business Administration, University of Benin, Benin City.

Jide, A. (2010).The structure of the Nigerian manufacturing industry, A Paper presented at the National Workshop on Strengthening Innovation and Capacity Building in the Nigerian Manufacturing Sector.

Manandhar, R., \& Tang, C (2002). The evaluation of bank branch performance using DEA: A framework. Journal of Business Research, 13, 1-17.

Mostafa, M. (2007). Evaluating the comparative market efficiency of top listed companies in Egypt. Journal of Economics Studies, 34(5), 430-452. http://dx.doi.org/10.1108/01443580710823239

Nordin, M., \& Said, F. (2010). Measuring the performance of 150 largest listed companies in Malysia. African Journal of Business Management, 4(13), 3178-3190. Nigerian stock exchange factbooks, 2010 issues.

Pandy, I.M. (2004). Financial Management. New Delhi: Vikas Publishing House PVT.

Raab. R., \& Lichty, R. (2002). Identifying sub-areas that comprise a greater metropolitan area: The criterion of country relative efficiency. Journal of Regional Science, 42, 579-594. http://dx.doi.org/10.1111/1467-9787.00273

Rousseau, J. J., \& Semple, J. H. (1995). Two-person ratio efficiency games. Management Sciences, 41(3), 435-441. http://dx.doi.org/10.1287/mnsc.41.3.435

Schmidt, S. S. (1976). On the statistical estimation of parametric frontier production Functions. Review of Economics and Statistics, 58, 238-239. http://dx.doi.org/10.2307/1924032

Sherman, H., \& Rupert, T. (2006). Do bank mergers have hidden or foregone value?: Realized operating synergies in one bank merger. European Journal of Operationa Research, 168, 253-268. http://dx.doi.org/10.1016/j.ejor.2004.05.002

Smith, P. (1997). Model misspecification in data envelopment analysis. Annals of Operations Research, 73, 233-252. http://dx.doi.org/10.1023/A:1018981212364

Staat, M. (2001). The effect of sample size on the mean efficiency in DEA: A comment. Journal of Productivity Analysis, 15, 129-137. http://dx.doi.org/10.1023/A:1007826405826

Stern, Z., Mehrez, A., \& Barboy, A. (1994). Academic department efficiency via DEA. Computer and Operations Research, 21, 543-556. http://dx.doi.org/10.1016/0305-0548(94)90103-1

Talluri, S. (2000). A benchmarking method for business process reengineering and Improvement. International Journal of Flexible Manufacturing Systems. http://dx.doi.org/10.1023/A:1008174116461

Tavares, G. (2002). A bibliography of data envelopment analysis (1978-2001). Ristor Research Report.

Yamane, Y. (1973). Statistics: An introductory analysis ( ${ }^{\text {rd }}$ ed.). New York: Harper \& Row.

Yomere, G. O., \& Agbonifoh, B. A. (1999). Research methodology in the social sciences and education. Benin City: Uniben Press. 